\title{
The Application of Metacognition in CET Band 4 Listening Comprehension
}

\author{
Caixia Wang, Ning Zhang \\ Shandong Jiaotong University at Weihai, P.R.China, 264200
}

Keywords: metacognition theory; listening comprehension; metacognitive instruction

\begin{abstract}
Metacognition, as a kind of deep cognitive activity, is the learner's self-monitoring of their own learning process, the knowledge and ability of the learner to take strategic actions for the effective organization of learning activities, and the concrete ways of using the strategies in the specific learning process. CET Band 4 listening comprehension test has been perplexing the majority of students. This paper begins with the basic concept of metacognition, and illustrates how to apply metacognitive theory to the improvement of English listening comprehension.
\end{abstract}

\section{Introduction}

The communicative effect depends on the speaker's ability to express, and more importantly on the listener's ability to listen. Understanding is a complex process in which the brain processes the acoustic signals received by the ears. In the second language learning, listening is more and more valued by language learners. In CET Band 4, the listening part is a torture for most students, and is also very easy to lose scores. In the course of teaching, the author tried to know more about students' listening exercises and training through informal interviews and discovered the serious lack of metacognitive knowledge in listening training. Combining college English teaching practice, this paper begins with the basic concept of metacognition, and illustrates how to apply metacognitive theory to the improvement of English listening comprehension.

\section{Metacognition Theory}

The term metacognition was first proposed by American psychologist Flavell in the 1970s.

Flavell $^{[1]}$ believes that metacognitive knowledge plays an important role in cognitive activities related to language use. Metacognitive ability generally includes two aspects: the cognition of cognition and the regulation of cognition.

\subsection{The Cognition of Cognition}

The Cognition of Cognition refers to the knowledge that the individual obtains from the cognitive activities, that is, the process and outcome of what factors affect the cognitive activities, how these factors work, how they interact with each other and so on.

It includes three aspects of knowledge: (1) Declarative knowledge, the knowledge of the facts themselves, and knowledge of what it is. (2) Procedural knowledge that is, the knowledge of "how to do sth." (3) Conditional knowledge that is, the knowledge about "why" and "when".

\subsection{The Regulation of Cognition}

The regulation of cognition means that the individual takes the ongoing cognitive activities as the object of consciousness, and monitors, controls and adjusts them constantly, actively and consciously. It covers three aspects: (1) Planning refers to the individual's choice of cognitive strategies and resource allocation; (2) Monitoring refers to the individual's understanding of their cognitive activities and their awareness of the implementation of the tasks. (3) Assessment refers to an individual's evaluation of the outcome and efficiency of his or her cognitive activities.

Metacognition is not only a static knowledge entity, but also a dynamic process. The cognition of the cognition is static and stable. The regulation of cognition is dynamic and unstable.

The two aspects of metacognition are independent and interconnected. The cognition of 
cognition is the basis of the regulation of cognition, in turn, each step of the regulation of cognition will enrich and develop the individual's cognition of cognition.

\section{Metacognition and English listening ability}

Metacognition plays a very important role in foreign language learning and affects the performance of foreign languages to a certain extent.

Coskun(2010) ${ }^{[2]}$, Kassaian\& Ghadiri(2011) ${ }^{[3]}$ did a research on the cognitive awareness of listening. It shows that metacognitive awareness is a higher level skill, which can not only improve the processing efficiency of listening process, but also ensure the success of listening activities. Qing Huang (2013) ${ }^{[4]}$ studied the effectiveness of metacognitive instruction in English listening for college non-English majors. La Mei Zeng (2015) ${ }^{[5]}$ did a research on metacognitive awareness and listening ability.

Listening comprehension is a process of decoding information and constructing meaning, which is a process of cognitive activity as well as a process of metacognitive activity.

As mentioned above, metacognitive ability covers three aspects. As for English listening comprehension, it can be summed up as follows:

(1) Declarative knowledge refers to the learners' understanding of various factors affecting listening comprehension, such as the social and cultural background of the target language country and language knowledge (pronunciation, words, meaning, etc.), and the learners' understanding of their own listening level.

(2) Procedural knowledge refers to learners' understanding of various listening strategies and skills, such as predicting before listening, how to activate schemata, and how to integrate discourse markers into listening practice.

(3) Conditional knowledge refers to the learner's knowledge of what appropriate listening strategies or skills to use and the reasons for using specific strategies or skills.

Similarly, as for English listening comprehension, another aspect of metacognition, i.e., the regulation of cognition can be summed up as follows:

(1) Planning refers to the rational selection of listening strategies or skills and the rational allocation of resources that affect listening comprehension activities, such as the prediction of the content to be heard before listening, the maintenance, control and rational distribution of attention in the process of listening;

(2) Monitoring means that the learner has an the awareness in the process of listening. The awareness makes the learner adjust and make a remedy when the choice of listening strategies or skills is not reasonable.

Assessment refers to the learner's serious self-examination and self-assessment on the effect of listening tasks, finding out the problem, summing up experience, so that same mistakes won't be made in future listening process.

\section{The concrete methods of improving students' metacognitive ability in listening comprehension}

\subsection{Enhance students' metacognitive awareness, increase the input of declarative knowledge, procedural knowledge and conditional knowledge in the process of listening comprehension}

The majority of students do not understand metacognition, and it's hard for them to apply metacognition to English listening comprehension. In response to this phenomenon, teachers should consciously enhance the students' metacognitive awareness by using the actual listening materials to demonstrate to the students.

As for the input of declarative knowledge, it is useful to increase students' practice of pronunciation and accumulation of listening vocabularies, introduce the cultural tradition of the target language country, the historical background and the differences of Chinese and Western culture, the different ways of thinking, explain the theories related to listening comprehension, such 
as schema theory, discourse marker theory etc.

For the input of procedural knowledge, teachers should introduce to students all kinds of listening strategies such as prediction, association, how to activate schemata, how to infer the content that will be heard by using such discourse markers as "so, but, know, too", etc.

For conditional knowledge, teachers should focus on how to use various listening strategies and the reasons for adopting some strategies for different listening tasks and objectives.

\subsection{Improve the regulation ability of cognition in the process of students' listening comprehension}

Because the regulation of cognition is a dynamic process, the author gives a dynamic description of the passage in CET Band 4(June, 2016)

There are three questions about this passage.

1) a) The importance of sleep to a healthy life.

b) Reasons for Americans' decline in sleep.

c) Some tips to improve the quality of sleep.

d) Diseases associated with lack of sleep.

2) a) They are more health-conscious.

b) They are changing their living habits.

c) They get less and less sleep.

d) They know the dangers of lack of sleep.

3) a) Their weight will go down.

b) Their mind function will deteriorate.

c) Their work efficiency will decrease.

d) Their blood pressure will rise.

First of all, before listening, a good plan should be made, the goal to be achieved should be made clear, is it an intensive listening with each word being understood or an extensive listening that the main idea will be gotten?

Choose an environment that is not easily disturbed when your mental state is good, adjust your emotions, keep your anxiety within a moderate range, and start concentrating, and tell yourself how much this concentration will last for at least as long as the listening task is concerned.

As the example shows, it is important for students to allocate the time intervals between first question and second question, second question and third question in advance. For example, 2/3 of the time interval (about 15 seconds) should be used to choose the answer in the first question, and $1 / 3$ of the time interval should be reserved to read the four options for the next question. Then quickly browse the four options for the first question. By the words: "sleeping, healthy life, blood pressure, etc", it can easily be predicted that the conversation is about sleep and health. And link with your own experience, the importance of sleep, how long you will sleep, the problems caused by bad sleep and so on.

In the process of listening, monitoring should be carried out actively. The sense of anxiety and failure caused by the ambiguity in the listening should be adjusted within a moderate range. After completing the listening task, evaluate the task, reflect on the strategies used in the process of listening.

\section{Conclusion}

Metacognition plays an important role in English listening comprehension. The input of declarative knowledge, procedural knowledge and conditional knowledge should be carried during teaching. For different tasks and situations, the regulation of cognition should be improved in students' listening comprehension.

\section{References}

[1] Flavell, J. H. 1979. Metacognition and cognitive monitoring: A new area of cognitive 
development inquiry [J]. American Psychologist, 1979, (10): 906-911.

[2] Coskun A. The Effect of Metacognitive Strategy Training on the Listening Performance of Beginner Students [J]. ROYAL, 2010, 4(1): 35-50.

[3] Kassaian Z, Ghadiri M. An Investigation of the Relationship between Motivation and Metacognitive Awareness Strategies in Listening Comprehension: the Case of Iranian EFL Learners [J]. Journal of Language Teaching and Research, 2011, 2(5): 1069-1079.

[4] Qing Huang, A Study of the Effectiveness of Metacognitive Instruction in English Listening for College non-English Majors. A thesis for the degree of master of education, 2013.

[5] La Mei Zeng A Study on the Development of English Majors' Metacognitive Awareness and English Listening Ability Overseas English 2015(09) 